\title{
TRADE EXPANSION, EMPLOYMENT AND INCOME DISTRIBUTION
}

\author{
H.W. Singer*
}

The literature on international trade in relation to development -even where it has been empirical rather than theoretical - has concentrated on the relationship between exports and growth of GNP, savings gaps and investment ratios, in accordance with the main parameters of the neo-classical growth model. The result has been to discover significant correlations between export growth and GNP growth and its neo-classical parameters, although this leaves open the question of which way the chain of causal relationship runs and also whether both export performance and rapid GNP growth are due to third factors rather than the result of a direct relationship. By contrast, little has been done to analyse export development systematically in relation to parameters which have come to the fore, perhaps particularly in the work of the IDS, for a reduction of poverty in developing countries, with consequent emphasis on income distribution, employment, technology and rural development. This neglect also applies to the work of international organizations (with the exception of UNCTAD) which have tended to treat employment policies, income distribution policies, technology policies etc. as the internal matters of developing countries.

This is at odds both with recent theoretical developments which tend to emphasize the influence of the global system and global relations on the internal structures of developing countries, and also with empirical findings about the impact of changes in trade relations upon the employment situation in developing countries. Thus it has been estimated ${ }^{1}$ that the decline in the share of developing countries in world trade between 1955 and 1970 has cost the developing countries 72 million jobs, or no less than 14.5 per cent of their 1970

*H.W. Singer is a Professorial Fellow of the Institute of Development Studies.

${ }^{1}$ William Tyler, 'Employment Generation and the Promotion of Manufactured Exports in Less Developed Countries: Some Suggestive Evidence'; paper prepared for the Kiel Conference on Problems of the International Division of Labour, mimeo, July 1973. 
labour force. Similar estimates related more specifically to agricultural exports have been made by the FAO and the World Bank, and although couched in terms of GNP they enable us to infer the great potential gain in employment which developing countries could enjoy as a result of liberalized imports of agricultural and agriculturebased products by the richer countries. Leaving aside the oil exporters, the volume of exports of developing countries during the period 1961 to 1972 has increased by less than $5 \frac{1 / 2}{2}$ per cent per annum, at just about the same rate as GNP, in spite of the enormous and unparalleled expansion of world trade. Contrary to the situation in developed countries, exports cannot therefore act as a spearhead of employment creation; while, because of unfavourable terms of trade and rising debt burdens from past investment and aid, import capacity remains so restricted as to impose tight limits to possible employment expansion. Yet employment creation has increasingly emerged as a chief instrument of reducing poverty, since the majority of those below the poverty line in developing countries are ablebodied persons of working age, or their dependents.

At the IDS, a start has been made in analysing trade liberalization in relation to employment and income distribution rather than economic growth in general. ${ }^{2}$ Whilst still somewhat provisional, this has already resulted in a number of clarifications and the collection of useful data. This first analysis was undertaken in the context of the idea of unilateral, non-reciprocal trade concessions which dominated the first approach towards the coming GATT negotiations, preceding the oil crisis and related upheavals. In any future work the emphasis would have to be much more on balanced trade expansion rather than unilateral trade 'liberalization'. While this would lend a different flavour to the analysis, the essential impact of increased export production, and/or better prices for exports, on employment and income distribution would remain substantially the same.

A conceptual framework for analysing employment effects of additional exports is more or less shared by most analysts. There is

\footnotetext{
${ }^{2}$ H.W. Singer et al., Trade Liberalization, Employment and Income Distribution: a first approach, IDS Discussion Paper no. 31.
} 
the direct employment provided by increasing export volumes; this may be zero if the initial expansion or liberalization is entirely in terms of higher prices obtained for exports (i.e. export earnings), perhaps as a result of commodity agreements, rather than improved access for additional exports. Then there is the indirect or linkage effect which can be sub-divided into backward linkage (additional domestically produced inputs) and forward linkage. For instance, if more shoes are exported there will be additional inputs of leather and, going further back, cattle hides, domestically produced equipment, glue, tanning materials, shoe laces etc. (backward linkage). The shoe exports will also lead to additional employment in transporting, shipping, insuring, trading (forward linkage). In calculating linkage effects it is important to avoid double-counting. If the export of shoes takes the place of previous exports of leather, there will still be a positive employment effect through the additional processing, and the value added. But it would be fallacious to add to this the employment created by the production of leather as being due to the export of shoes, since shoe exports take the place of leather exports.

Besides the direct and indirect (linkage) employment effects, we can distinguish the multiplier effects arising from the expenditure of the additional incomes earned through expanded direct and indirect employment. Increased export earnings due to higher prices would have employment multiplier effects in the same way as increased export volumes, although the two effects are not necessarily identical. The calculation of multiplier employment and income effects again requires specific analysis of all actual benefits from the higher incomes obtained by the direct and indirect producers of the additional exports; the distribution of the increased incomes throughout the different stages of the producing and distributing chain would be of crucial importance, as well as distribution between national producers and foreign investors; empirical analysis of this is often difficult.

Finally, there is the very important neo-classical type of balance-ofpayments employment effect; this is the expansion of employment and creation of additional incomes made possible by the removal or relaxation of the foreign exchange bottleneck due to higher export earnings. Here again it is important to avoid double-counting; to the 
extent that the original increase in exports requires additional imported inputs, or to the extent that the multiplier effects of additional incomes generated involve additional imports, the foreign exchange bottleneck is not eased, and no additional investment for employment creation is possible. In other cases, the additional investment may be needed to cope with supply constraints and capacity limitations arising directly from the expansion of exports and related production of required inputs. However, in many specific situations increased exports will make possible the import of additional capital equipment which would complement the available labour supply in new lines of production, increasing employment and reducing poverty.

Thus there are four headings under which the employment effect of additional exports can be analysed: direct, indirect, multiplier, and balance of payments. Not enough empirical or measurement work has been done for us to say very much about the relationship between these four types of additional employment, except that in most situations direct employment creation will be only a minor part of the total employment effect. Hence it would be misleading to try to deduce the impact on income distribution and on poverty from the direct employment effect only.

The report of the Philippines ILO Employment Mission ${ }^{3}$ contains some data ${ }^{4}$ which would indicate that the linkage employment effects alone were over three times the direct employment effects in the case of traditional consumption goods; over ten times in the case of export oriented manufacturing; over two-and-a-half times in the case of modern intermediate goods; and also over two-and-a-half times in the case of modern capital goods. However, this calculation when applied to the employment effect of additional exports may include elements of double-counting of the kind discussed above, in so far as it assumes that the exports of the various classes of goods analysed are entirely additional and are not replacing exports of less

${ }^{3}$ Sharing in Development: A Programme of Employment, Equity and Growth for the Philippines, ILO Geneva, 1974.

${ }^{4}$ Special Paper no. 19: 'Intersectoral linkages and direct and indirect employment effects'. 
manufactured or primary products. In the case of agricultural products where the backward linkages are so much less, the difference between direct and indirect employment effects is of course narrowed. But even so it is worth noting that the total (direct and linkage employment effects) is still much greater for agricultural products than for manufactured products or construction activities. Even export crops provide twice the volume of employment for a given value of exports than manufacturing, the domestic food crops twice as much again as export crops. Within the manufacturing sector, export-oriented manufacturing goods create almost twice as much employment as modern capital goods or intermediate goods, and traditional consumption goods create three times as much as exportoriented manufactures. ${ }^{5}$ Total net (domestic) linkages for agriculture were 50-100 per cent higher than for most industries in the case of India; and 100-500 per cent higher in the case of East Pakistan (Bangladesh) and West Pakistan (Pakistan). ${ }^{6}$

Apart from the greater employment and presumably also income distribution effects of agricultural exports, the other fact which stands out clearly from these and other data is the greater employment effect of traditional types of goods, and of export-oriented types of production. This leads to two conclusions:

(a) the importance of sectoral or commodity selectivity in promoting exports designed for maximum impact on employment and income distribution; and

(b) the fact that the natural export products of developing countries (primary, processed and labour-intensive products) tend to be more employment-intensive than modern sector production for the home market, especially under conditions of protection and factor price distortion.

This is not a novel observation and has in fact been extensively dealt with in economic literature. ${ }^{7}$ Empirical data are less frequent, but

\footnotetext{
${ }^{5}$ All data drawn from Philippine Employment Mission, op. cit.

${ }^{6}$ S.N. Acharya and B.R. Hazari, 'Linkages and Imports: a comparative study of India and Pakistan', Journal of Development Studies, October 1971.

${ }^{7}$ e.g.(i) Little, Scitovsky and Scott: Industry and Trade in Some Developing Countries, for OECD Development Centre, 1970.

(ii)ibid: Employment, Incomes and Equality. A strategy for increasing productive employment in Kenya. ILO Geneva, 1972.
} 
for Turkey, for example, it has been estimated that output per unit of investment was 3.4 times higher, valued at international prices for export industries, than for import-substituting industries. ${ }^{8}$ This would have meant not only more direct and linkage employment (presumably at least 3.4 times as much), but also an increased import capacity 3.4 times larger than that set free by import substitution, and a correspondingly enhanced potential balance of payments employment effect. Recent studies in the field of manufacture have shown quite conclusively that the pattern of exports from developing countries is strongly concentrated at the labour-intensive end of manufactured products, in line with the Heckscher-Ohlin factor proportions theory. ${ }^{9}$

This link between the degree of trade liberalization or freedom of access to markets on the part of the developing countries and the nature of their overall technology deserves special emphasis. Freer trade is the means by which the developing countries can bring into play their abundant labour supplies as well as their natural resources, and therefore trade expansion tends to be equivalent to a shift in technology in the direction of greater labour intensity. The labour intensity of production is not only determined by the technology of producing given products, but also, very importantly, by the output mix. Additional trade will give added importance to labour-intensive products in the total output mix. It ill behoves richer countries to preach to developing countries the virtues of labour-intensive or intermediate technology, while at the same time through trade restrictions denying them one of the most important and obvious ways of employing such a technology.

In the same direction, it has been pointed out in the ILO employment missions, especially the one for Colombia, ${ }^{10}$ and confirmed by

\footnotetext{
${ }^{8}$ A.O. Krueger: 'Some Economic Costs of Exchange Control: the Turkish case', Journal of Political Economy, October 1966.

${ }^{9}$ See, for instance: A.H.M. Mahfuzur Rahman, Exports of Manufactures from Developing Countries, Centre for Development Planning, Rotterdam; Rotterdam University Press, 1973.
}

10 Towards Full Employment. A Programme for Colombia, ILO Geneva, 1970. 
subsequent analysis, ${ }^{11}$ that increased labour intensity initially induced by trade expansion will in turn have a multiplier effect in generating further labour-intensive employment and hence more equal income distribution in several senses:

(a) the demand pattern of lower income groups tends to be for more labour-intensive products, so that the employment multiplier effect tends to be positively correlated with the initial employment effect; the higher the initial employment, the higher also the former;

(b) the linkages of the products consumed by lower income groups tend to be more labour-intensive and hence the linkage effect also tends to be positively correlated with the direct employment effect;

(c) the import content of both direct linkage and multiplier employment from products produced by lower income groups is less than for products consumed by higher income groups, and this would tend to increase the domestic employment impact as well as the balance of payments effect of such additional initial employment. ${ }^{12}$

An interesting corollary of this is that trade expansion tends to result in a more equal income distribution in developing countries by enhancing the share of labour as against capital; while in the developed countries - at least as far as trade with the developing countries is concerned - it will have the opposite effect, resulting in a more unequal income distribution. This to some extent explains the political resistance in developed countries to more liberal imports from the developing countries, at least in the absence of redistributive social policies or effective compensation and adjustment procedures. ${ }^{13}$

11 Felix Paukert et al., Redistribution of Income Patterns of Consumption and Employment - A Case Study for the Philippines, working paper prepared for ILO World Employment Research Programme, Geneva, May 1974.

12 It should be pointed out, however, that this last element was not confirmed in the Philippines case by Felix Paukert et al., op. cit.

13 This has also been pointed out by Michael Lipton, see 'Confrontation Versus Co-operation: Poor Countries' Dwindling External Options; Bargaining; and the Case for Multiple Bilateralism' in IDS Bulletin special issue 'Oil and Development', vol. 6 no. 2, October 1974 . 
The study undertaken at the IDS ${ }^{14}$ has also brought out very clearly how the specific approaches to trade liberalization, such as particularly, the 'Kennedy Round' of GATT negotiations and the EEC Preference Scheme (GSP), ${ }^{15}$ have been almost systematically weighted against the poorer countries and against those commodities and processing margins that are of particular value for employment creation and hence reduction of poverty in developing countries. Both tariff and non-tariff barriers tend to weigh more heavily against products from developing countries - e.g. in 1969, 11 per cent of all imports of developed countries were subject to non-tariff barriers compared with 28.2 per cent of their imports from developing countries. ${ }^{16}$ In this sense trade policy has been at cross purposes with the professed aims of aid policy and development policy in general. The question therefore arises of how a future policy of trade liberalization, or perhaps more realistically, a future policy of balanced trade expansion with the oil deficit countries of the Third World, can be geared more effectively and more purposefully to a direct attack on poverty and unemployment in the Third World. Here again, the IDS 'first approach' study has brought out a number of points both of method and of substance on which relatively little research has been done and on which it is desirable also to obtain more empirical data.

The principle which obviously suggests itself is that of 'country selectivity'. Trade concessions should be concentrated on those countries where they are most likely to result in increased employment and increased incomes for people below the poverty line. Two

\footnotetext{
14 IDS Discussion Paper no. 31, op. cit.

15 The EEC Preference Scheme is presently due to be significantly improved, especially by including processed agricultural products, liberalizing the level of ceilings under GSP preference, drastically reducing the number of sensitive products where the EEC reserves the right of cancellation of preference, and a modification of the rules of origin which will remove the present bias against regional co-operation among developing countries. These are very significant improvements as far as developing countries as a whole are concerned, but it is not clear at this moment whether they would significantly affect the bias within the scheme against poorest countries and against poor producers. The nost significant improvement from that point of view would seem to be the extension of the scheme to processed agricultural products.
}

16 UN Economic and Social Council, Project IV, p. 13. 
questions immediately arise once the principle is stated in this general form. First, how can country selectivity be reconciled with traditional methods of trade negotiations? The general principle of trade negotiations is precisely to rule out country selectivity, which is assumed to introduce an undesirable 'political' element into the 'neutral' procedure of peaceful trade expansion, and to be incompatible with the ideal of global freeing of trade. This 'neutral' or 'non-political' character of trade concessions and trade liberalization, however, has already been heavily diluted by such factors as regional integration, preferential schemes such as EEC relations with associates and the EEC 'hierarchy' as opposed to a global policy, by the introduction of the concept of 'least developed countries' for which special trade concessions might be permissible, as well as by the general introduction of the concept of non-reciprocity in Part IV of the GATT Rules. It is quite possible that in future this dilution will be further increased through the spread of bilateral arrangements for balanced trade expansion between countries with oil-induced balance of payments deficits. ${ }^{17}$ But even so, there remains a conflict between country selectivity and the prevailing principles of trade negotiations, as most clearly embodied in the Most Favoured Nation clause and also in the concept of the 'principal supplier' governing trade negotiations. ${ }^{18}$

Second, how should the principle of country selectivity be applied, provided it is agreed and can be reconciled with existing procedures? Clearly, it could be applied in two different ways:

(a) specific efforts could be made to expand the exports of the poorest countries, on the assumption that the poorer the benefiting country the more likely it will be that the beneficiaries will also be poor; or

(b) an attempt could be made to select countries which, although not necessarily poorer than others within the Third World category, have the most effective policies for shifting resources, including those resulting from trade expansion, towards the poorer sections of their population.

17 Michael Lipton, op. cit.

18 IDS Discussion Paper no. 31, op. cit. 
Again, once these two possibilities are stated a number of obvious problems arise. Taking (a) first (the concentration of benefits on poor countries), the first question is where to draw the line in identifying the main beneficiaries of such a policy. The problems involved have already been acutely felt in connection with the UN list of least developed countries which, for largely irrelevant reasons, leaves out some of the largest and poorest countries such as India and Bangladesh. A related problem is that of the criteria to be used to establish such a list; in the case of the UN list three criteria were used:

per capita GNP;

illiteracy rate;

share of manufacturing production in GNP.

Other criteria and combinations of criteria are equally plausible. But perhaps the most important doubt is whether the basic assumption is justified, i.e., that benefits shifted to poorer countries will also ensure that the benefits go to poorer people. It is understandable that the UN, which is based on the principle that governments represent the interests of their people, should make this identification. But it does not follow that this is realistic or that developed countries in contemplating their national trade policies would be willing to make the same assumption. (An obvious example would be trade concessions made to Haiti, which is on the UN list of least-developed countries). But although data to support a firm conclusion are not available, it is plausible to assume that the poorer developing countries have also a more unequal income distribution, perhaps for similar reasons to those which explain why the developing countries as a whole have a more unequal income distribution than the developed countries as a whole. This might not apply to the very poorest countries, because where the total volume of resources is so small, the poorer people of those countries could not conceivably be alive today if the income distribution did not have a certain degree of equality, particularly as regards the poorest 20 per cent of the population. But be that as it may, the problem remains that additional resources shifted to the poorer or poorest countries through trade expansion might well benefit the richer groups within those countries, or foreign investors operating in them, or export and import traders of the developed countries controlling their trade. All 
this will depend on the specific situation, policies and power structure within each of these countries. The principle of fungibility must be assumed to apply, i.e., even if the direct and immediate benefits from the additional trade accrue to the poorest producers within the benefiting poorer countries, if the general policies of the country are such as to shift resources in the direction of richer groups or foreign investors, this will determine the ultimate impact of expanded trade.

This is the principal argument for adopting the second course, i.e. selecting those countries for trade expansion which from their general structure and policies can be assumed to shift any additional benefits to the poorer sections of their people. This approach is strengthened by the importance given in the discussion above to linkage employment, multiplier employment and balance-ofpayments employment effects as against the direct employment impact of producing the additional exports. For the extent and nature of these indirect effects depend very much upon internal policies and internal structures. But the obvious difficulty is how to separate the sheep from the goats - how to identify those countries with a 'good' income distribution policy from those with a 'bad' one. This will involve difficult decisions which may go against the grain of the political interests of the major trading countries, the more so since such decisions must remain to some extent arbitrary and a matter of judgment, and for which in any case at the present time the necessary data are largely lacking, owing to the obsession of statisticians with aggregate production and GNP figures.

What criteria could be used to distinguish 'good' from 'bad' countries? The possibilities seem to be, present equality of income distribution (provided we had the necessary data); rates of employment and unemployment (for which we have practically no comparable data at all, in spite of the efforts of the ILO World Employment Programme); the percentage of the population below the poverty line (although that depends to some extent on the level of average incomes and on the existence of comparable poverty lines).

But is there any guarantee that countries which in the past have had 'good' policies will continue to do so in the future, or vice versa? In 
practice it would seem best to link trade concessions with leverage by the main trading countries to induce countries to move to a 'better' policy - but will such leverage not be an intolerable interference with the domestic affairs of developing countries and how in practice should such leverage be designed and implemented?

We may also consider that the country unit is somewhat arbitrary and misleading in measuring average income levels. For example, while Brazil would clearly not qualify for special priority on any principle of country selectivity, the north-east contains people whose average income is extremely low and should qualify for priority concessions (and their actual number is larger than that of most developing countries). This would suggest a policy, in trade negotiations, of singling out the export products of such very poor regions within richer countries (for instance, for Brazil the concessions would be made on export products other than coffee, which comes from the richer south). There is certainly scope for such a procedure, although it is subject both to the objection of interference in internal affairs, and to the tremendous administrative complication of trade negotiations which would result. Moreover, there is always the fungibility objection: a country with 'bad' policies will always find ways and means of diverting benefits away from poor regions to the richer regions. Finally, there is the objection that a poor region within a richer country should be looked after by the rest of the country, and not have to rely on the international community for special equalizing trade concessions.

The other possible approach is based on commodity selectivity, in place of (or in combination with) country selectivity. A list could be drawn up in which commodities were ranked either according to the degree to which they were produced by poorer people, or the degree to which they are employment-intensive, or a combination of the two.

The trouble with this approach is that the income level of the producers as well as the employment intensity of production depend strongly upon the mode of production. In the case of agricultural products, for instance, the employment intensity of production would normally be high and the income level of the beneficiary 
would normally be low in the case of production on small farms and vice versa for production on large estates or plantations. Participation in export production, and specifically response to new export possibilities, may often be concentrated on the larger estates so that the benefits would not accrue in conformity with employment/ income distribution criteria, even though the bulk of the present or domestic production of the commodity concerned might correspond to such criteria. Possibly the best application of the principle of commodity selectivity is by sectors: there is convincing evidence that agricultural products in general have a higher employment intensity and that the rural producer tends to be poorer than the urban producer, so that expanded trade in agricultural products is most likely to satisfy the distributive criteria. The same would apply to the processing of agricultural products, particularly when this is done on a small scale and in rural locations.

In trying to channel the benefits of expanded trade to the poorer countries, to poorer producers and to particularly labour-intensive commodities, the proposal has also emerged ${ }^{19}$ to allocate free floor quotas to the poorer among the developing countries, or to new exporters not previously listed among the 'principal suppliers', or specifically for commodities which study has shown to be specially important for rural development or specially labour-intensive or specially associated with poor producers (e.g. handicraft products). It is also clear that the poorer countries, poorer producers and new exporters also are in particular need of special long-term guarantees and actual help in setting up and developing export industries. Once we take seriously the idea of trade as a tool in the fight against poverty, it is clear that trade promotion for the benefit of developing countries must go far beyond trade concessions. A further offshoot of this line of thinking is the idea that adjustment assistance must be available not only to workers and producers in developed countries who might otherwise offer resistance to more liberal imports from poorer countries, but also to developing countries, in two forms:

(a) adjustment assistance for the import-substituting industries which have been built up on the basis of protection and distorted

19 Originally developed by Angus Hone, one of the collaborators in IDS Discussion Paper no. 31, op. cit. 
factor prices, and which might suffer even in a controlled transition towards an export orientation. Care would obviously have to be taken that such payments did not benefit foreign investors and national producers who have made good profits on the basis of past protection and inducements, and can well afford to carry the cost of transition themselves. Also, such payments must not be allowed to become a subsidy for continued existence rather than for a smoothed transition.

(b) the very export industries that would be built up on the basis of better market access offered by the rich countries need protection against sudden and unforeseen disruption suffered when the rich countries, for reasons of national policy, suddenly invoke escape clauses or restrict access after initially offering it to developing countries. This is an aspect of adjustment assistance which deserves further exploration. ${ }^{20}$

${ }^{20}$ A first study of this is now proceeding at the IDS within the framework of an OECD research project on adjustment assistance problems. 